universities; for it was in Prague at the World Students' Congress in November 1945 that an important part of the work on the foundations of this new organisation was done. The first ordinary issue of the British Medical Students' Journal (published from B.M.A. House, Tavistock Square, London, W.C.I) is appearing in October, and thereafter one issue will be published each term, each containing essays, articles and news interesting to medical students. An indication of the kind of fare to be provided is given by the announcement in this issue that the October number will contain articles by Sir Joseph Barcroft on fœtal respiration, by Prof. Samson Wright on hypertension, by Dr. James Marshall on penicillin and venereal disease, and by Dr. Charles Hill, secretary of the British Medical Association, on the National Health Service, together with news, short stories and articles contributed from all over Britain. An interesting feature will be a section devoted to nurses who wish to improve the efficiency and conditions of their service. It is particularly gratifying to know that medical students, like so many other sections of the community, wish to help the nurses to attain the status, remuneration and conditions of life and work which are merited. by the important part they play in modern medical practice. 6,6

\section{Man's Ancestry in Africa}

FURTHER detail $\%$ the circumstances and character of the recentl tundunced discovery of relics of two early form tif extinct anthropoids have now been recorderl.t Dr. L. S. B. Leakey (The Times, August 23). T Vo lower jaws were found within $15 \mathrm{ft}$. of one ano hes by Dr. Leakey, while on leave from war-time duties, in the Lower Miocene deposits of Rusinga Island which lies at the mouth of Kavirondo Bay in the north-east corner of Victoria Nyanza. Of these two specimens, one has since been identified as belonging to the genus Proconsul, the other as belonging to the genus Xanopithecus. These two genera with a third, Limnopithecus, were first discovered and described by Dr. A. T. Hopwood in 1931 when working as a member of the "Third Leakey East African Archæological Expedition" on the Lower Miocene deposits at Koru in Kenya. Further discoveries of fossil ape material were made by Dr. Leakey and other members of his expedition at Rusinga and elsewhere between 1931 and 1935. Dr. Hopwood regarded Proconsul as a very close relative of the chimpanzee, and Limnopithecus as being of the same stock as the gibbons. When the new specimens now recorded by Dr. Leakey had been cleaned and examined it was found that the Proconsul jaw, which is very nearly complete and the most nearly perfect of any fossil anthropoid jaw yet discovered, did not show so close a relationship to the chimpanzees as Dr. Hopwood had thought. It was, in fact, much more human in certain characters than not only the chimpanzee jaw but also that of the Piltdown skull. The chin is more vertical, there is no simian shelf (the ledge of bone on the anterior aspect of the symphysial area of the jaws of all apes) and the condyle in many ways is more like that of a man than an ape. Of possible alternatives, Dr. Leakey favours the view that in Proconsul we have a near approach to an ape-like form from which the human stem eventually was evolved, and goes on to suggest that notwithstanding recent tendencies to look to Asia, Africa may well be the place of origin of man. The Old Moon in the Arms of the New
MонD. A. R. KH Begump Holar 4tromy (53, No. 7, August 1945) in which it id aldested that variations in the lunar earthshine ma be partly due at times to intense meteoric activity on the moon. It is not necessary to suppose that the moon has an atmosphere to make this theory feasible, because bombardment of the moon's unprotected surface could explain the appearance. A profitable piece of research would be to try to corre. late the luminosity of that portion of the moon visible under earthshine with meteoric displays observed on the earth. Reference is made to a paper by Walter $\mathrm{H}$. Haas, "Concerning Possible Lunar Meteoric Phenomena" (Contributions of the Society for Research on Meteorites, 3, 98), which describes two lunar flares that he observed with his 4-in. refractor in 1938. It would be interesting to know what conclusions, if any, have been drawn from these observations.

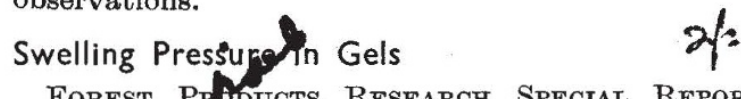

Forest Pf joucts Research Special Report No. 6 (If a on : H.M. Stationery Office. 1s.) deals with "flling Stresses in Gels, and the Calculation of helastic Constants of Gels from their Hygroscoplic Properties". The results are of importance in the use of composite wood products or synthetic plastics derived from natural fibres, and the general aspects of the subject are also dealt with. The abstruse theory is concisely but adequately set out, and the tendency of the paper is theoretical, very little experimental material being presented.

\section{Announcements}

THe Royal Astronomical Society will celebrate the discovery of Neptune on September 23, 1846, by holding a conversazione on October 8. Prof. W. M. Sman, regius professor of astronomy in the University of Glasgow, will deliver an address on "John Couch Adams and the Discovery of Neptune", and there will be exhibits relating to Adams, Le Verrier, Tycho Brahe and John Flamsteed.

Sir James Chadwick, professor of physies in the Univgsity of Liverpool, will deliver the Melchett Leglure for 1946 of the Institute of Fuel on October 8, at 6.0 p.m., at the Central Hall, Westminster, London, S.W.1 ; he will speak on "Atomic Energy and its Applications"

DR. RAMSвоттом is giving lectures at the British Musfam (Natural History) on edible fungi on Mondays and Wednesdays at 2.30 p.m. The lectures will be continued until October 16.

The Committee of Privy Council for the Organisa. tion ay Development of Agricultural Research has appgited Dr. A. N. Drury, Dr. Joseph F. Duncan and Prof. T. J. Mackie to be members of the Agricultural Research Council. They succeed Prof. D. Keilin, Major James Keith and Prof. F. T. Brooks, whose terms of office have expired.

The Committee of Privy Council for Medical Reseaych has appointed Mr. C. A. B. Wilcock, M.P., Prof C. A. Lovatt Evans (Jodrell professor of pbysiology in the University of London) and Prof. R. A. Peters (Whitley professor of biochemistry in the University of Oxford) to be members of the Medical Research Council. 